\title{
Deterioration of fracture healing in the mouse model of NF1 long bone dysplasia ${ }^{\text {is }}$
}

\author{
T. El Khassawna a,b,1, D. Toben ${ }^{\text {a,b,1 }}$, M. Kolanczyk ${ }^{\text {c,d,* }}$, K. Schmidt-Bleek ${ }^{\text {a }}$, I. Koennecke ${ }^{\text {a,b }}$, H. Schell ${ }^{\text {a }}$, \\ S. Mundlos ${ }^{\text {b,c }}$, G.N. Duda ${ }^{\text {a,b }}$ \\ a Julius Wolff Institute and Center for Musculoskeletal Surgery, Charite Universitätsmedizin Berlin, Germany \\ ${ }^{\mathrm{b}}$ Berlin Brandenburg Center for Regenerative Therapies (BCRT) \\ c Max Planck Institute for Molecular Genetics, Berlin, Germany \\ d Institute for Medical Genetics, Charité-Universitätsmedizin Berlin, Germany
}

\section{A R T I C L E I N F O}

\section{Article history:}

Received 17 February 2012

Revised 1 June 2012

Accepted 13 July 2012

Available online 31 July 2012

Edited by: Bjorn Olsen

\section{Keywords:}

Neurofibromatosis

Bone healing

Tibial dysplasia

NF1

Psudarthrosis

Nf1Prx1

\begin{abstract}
A B S T R A C T
Neurofibromatosis type 1 (NF1) is an autosomal dominant genetic disease resulting from inactivating mutations in the gene encoding the protein neurofibromin. NF1 manifests as a heritable susceptibility to tumours of neural tissue mainly located in the skin (neurofibromas) and pigmented skin lesions. Besides these more common clinical manifestations, many NF1 patients (50\%) have abnormalities of the skeleton. Long bones are often affected (usually the tibia) and the clinical signs range from bowing to spontaneous fractures and non-unions. Here we present the analysis of bone fracture healing in the Nf1 ${ }^{\text {Prx1}}$-knock-out mouse, a model of NF1 long bone dysplasia. In line with previously reported cortical bone injury results, fracture healing was impaired in Nf1 ${ }^{\text {Prx1 }}$ mice. We showed that the defective fracture healing in Nf1 ${ }^{\text {Prx1 }}$ mice is characterized by diminished cartilaginous callus formation and a thickening of the periosteal bone. These changes are paralleled by fibrous tissue accumulation within the fracture site. We identify a population of fibrous tissue cells within the Nf1 deficient fracture as alpha-smooth muscle actin positive myofibroblasts. Additionally, histological and in-situ hybridization analysis reveal a direct contact of the fracture site with muscle fascia, suggesting a possible involvement of muscle derived cells in the fracture deterioration.
\end{abstract}

(c) 2012 Elsevier Inc. All rights reserved.

\section{Introduction}

Bone fracture healing is a complex physiological process, which aims to restore pre-injury structure and function of bone. It is thought to reflect the embryonic processes of skeletal development [1]. Endochondral fracture healing requires primary cartilage formation and a subsequent replacement of the cartilaginous soft callus by hard bony callus. Failure in either of the two steps of the process leads to a delayed of healing or non-union (pseudoarthrosis). More than $50 \%$ of all reported cases of sever bone healing deficiencies are diagnosed in association with the neurofibromatosis type 1 (NF1) [2]. NF1 is a heritable tumour predisposition syndrome (the main tumour type being neurofibromas) with multiple other clinical features caused by mutations in the NF1 gene. NF1 codes for neurofibromin (Nf1), a

Abbreviations: Nf1, Prx1; Nf1Flox, X Prx1Cre; BV, bone volume; TV, total volume; $\mathrm{BMD}$, bone mineral density.

Conflict of interest: All authors state that they have no conflicts of interest.

* Corresponding author at: Ihnestr. 73, D-14195 Berlin, Germany. Fax: + 49308413 1385.

E-mail addresses: thaqif.el-khassawna@charite.de (T. El Khassawna), daniel.toben@charite.de (D. Toben), kolanshy@molgen.mpg.de (M. Kolanczyk), katharina.schmidt-bleek@charite.de (K. Schmidt-Bleek), ireen.koennecke@charite.de (I. Koennecke), hanna.schell@charite.de (H. Schell), stefan.mundlos@charite.de (S. Mundlos), georg.duda@charite.de (G.N. Duda)

1 These authors have contributed equally. tumour suppressor protein known to regulate the GTPase-Ras via hydrolyzation of GTP. NF1 patients exhibit spectrum of skeletal manifestations including generalized osteoporosis as well as localized dysplasias e.g.: dystrophic scoliosis, sphenoid wing dysplasia and dysplasia of the long bones (most often tibia) [3-5]. Tibia bowing in NF1 increases risk of fractures, which can progress to non-healing pseudarthrosis. Biallelic inactivation of NF1 was reported in the affected pseudarthrotic tissue suggesting second hit mutations might be involved in the tibial dysplasia pathogenesis [6,7]. Several mouse models have been developed to study the role of NF1 in bone development and regeneration. Since germ line Nf1 inactivation is embryonic lethal [8] and the $\mathrm{Nf} 1^{-1+}$ mice did not show bone healing deficiency in the tibial midshaft fracture model [9], biallelic inactivation models were developed. These included osteoblasts specific inactivation $\left(N f 1^{-/-}{ }_{o b}\right)$ [10], limb mesenchyme specific inactivation

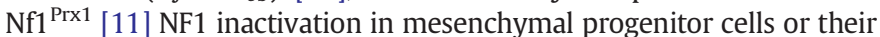
progeny [PeriCre(+);Nf1(flox/-) and Col2.3Cre (+);Nf1(flox/-)] on the haploinsufficient background [12]. A local Nf1 inactivation in the fracture site with help of adenoviral Cre delivery in $\mathrm{Nf1} 1^{\text {flox/flox }}$ and $\mathrm{Nf} 1^{\text {flox/- }}$ mice was recently reported [13]. Studies of these and other models revealed an important role of Nf1 in regulation of chondrocyte and osteoblast [14] as well as osteoclasts differentiation and proliferation $[15,16]$. Additionally, both clinical reports and animal models indicate that loss of NF1 results in vascular changes associated with increased proliferation of vascular smooth muscle cell [17-19]. 
In the current study we took advantage of the previously described Nf1 ${ }^{\text {Prx1 }}$ mouse model in which Nf1flox/flox allele is inactivated by cre recombinase in the entire limb bud mesenchyme yielding knock-out in the appendicular skeleton as well as limb skeletal muscles [20]. We have previously shown that $\mathrm{Nf} 1^{\mathrm{Prx} 1}$ mice have impaired cortical bone injury regeneration $[21,22]$. This type of healing relies predominantly on desmal osteogenesis while the fracture healing involves mainly endochondral bone formation, the process which was not previously analyzed in Nf1 ${ }^{\text {Prx1 }}$ mice. Here we investigate how NF1 ablation in the bone and the nearby skeletal muscles affects bona fide fracture healing. Our results show that $N f 1$ is required for the normal cartilaginous callus formation and its absence results in the non-healing fracture situations similar to the status of a pseudarthrosis in humans.

\section{Material and methods}

\section{Experimental design}

Closed fractures of femoral bones were induced in control mice and mice deficient for Nf1 in appendicular mesenchyme ( $\mathrm{Nf} 1^{\mathrm{Prx} 1}$ ) (see Animal model section). The resulting callus tissue was analyzed at four time points Day 7 (D7), Day 10 (D10), Day 14 (D14) and Day 21 (D21) post fracture induction. The chosen time points reflected
A
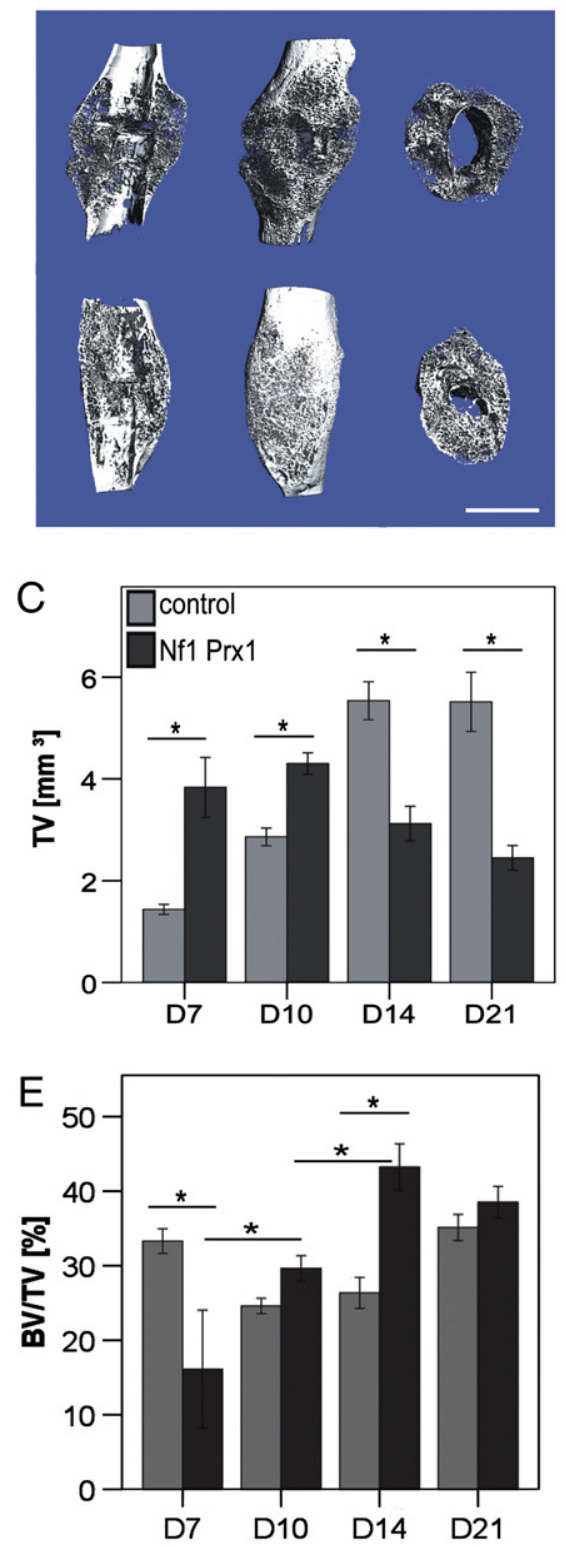

B

D14
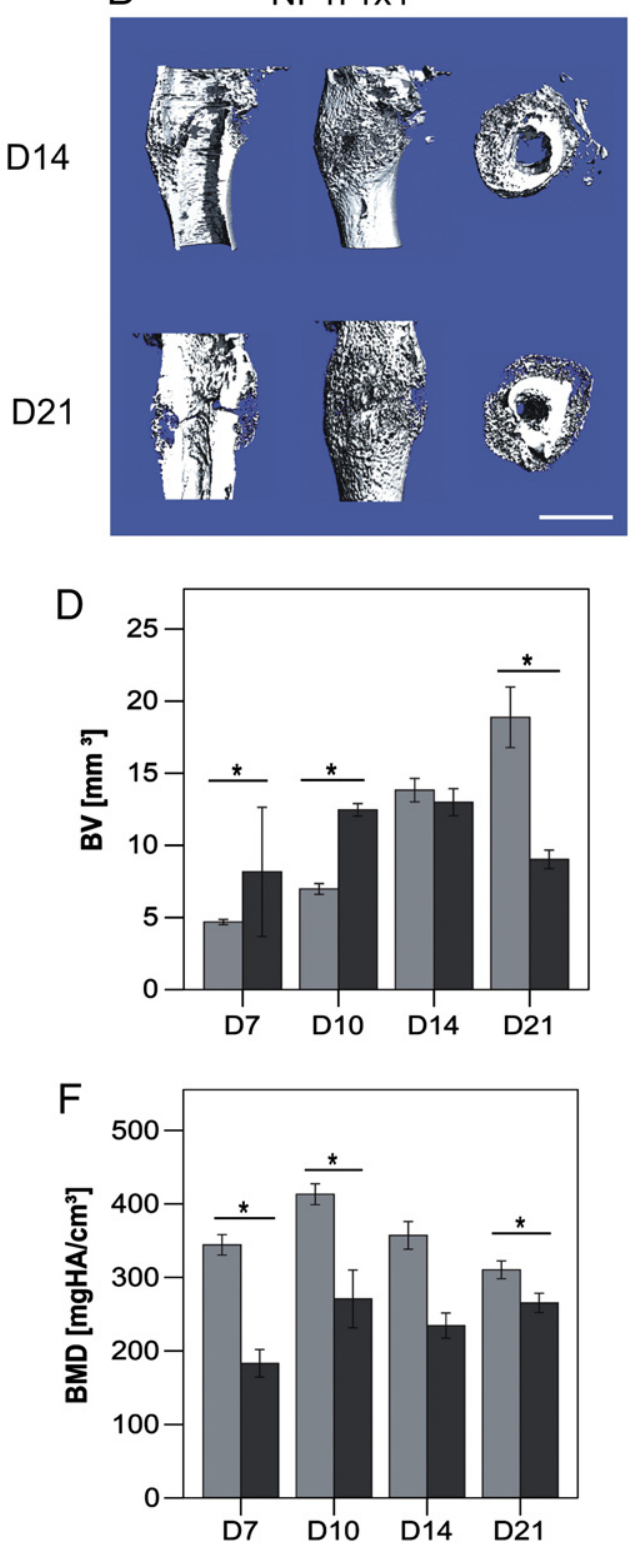

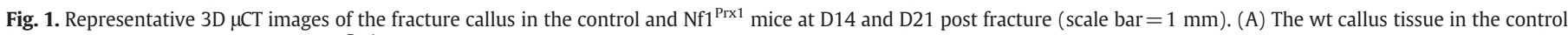

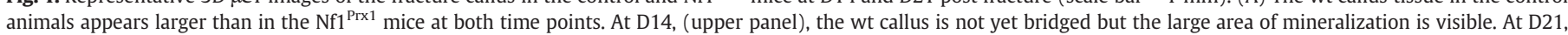

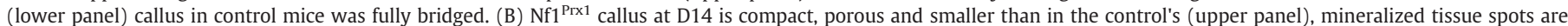

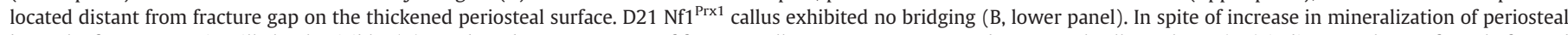

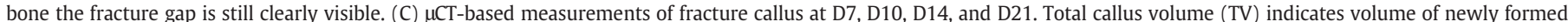

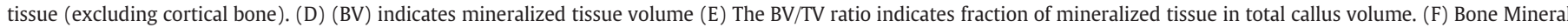

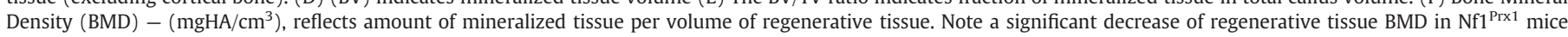
compared with controls at all healing stages $\left({ }^{*}=\mathrm{p} \leq 0.05\right)$. 
consecutive stages of the healing process in WT mice: D7 - cartilage is evident, D10 - cartilage formation reaches maximum, D14 - callus cartilage is largely replaced by bone [22], D21 - fully bridged bony callus. For molecular analysis of the healing process we used 5 animals per group $(\mathrm{N}=5)$, for $\mu \mathrm{CT}$ analysis, biomechanical testing as well as histological analysis we used 8 animals per group $(\mathrm{N}=8)$.

\section{Animal model}

Male wild type C57BL/6N mice (Charles River Laboratories) were used as controls. The Nf1 ${ }^{\operatorname{Prx} 1}$ mice were generated as previously described [23]. Shortly, male mice heterozygous for Nf1flox allele $\left(\mathrm{Nf} 1^{\text {flox/wt }}\right.$ ) and carrying cre-recombinase gene under Prx1 promoter $\left(\mathrm{Prx}^{\mathrm{cre}+}\right)$ were crossed with homozygous NF1flox (Nf1 ${ }^{\text {flox/flox }}$ ) female mice. Prior to breeding all strains were back crossed for several generations onto $\mathrm{C} 57 \mathrm{BL} / 6 \mathrm{~N}$ strain. All protocols were approved by the local ethics commission (Landesamt für Arbeitsschutz, Gesundheitsschutz und technische Sicherheit, Berlin-Germany registration number: $G$ 0282/07), and done under consideration of the national animal welfare guidelines for the care and use of research animals.

\section{Surgical procedure}

Eight-week-old male mice were used to generate unilateral standard closed fractures in the left femur using Bonnarens and Einhorn's [23] three-point bending method under $2.5 \%$ isoflurane inhalation anaesthesia in oxygen. Prior to surgery mice received also buprenorphine ( $1 \mathrm{mg} / \mathrm{kg}$ body weight; Temgesic, Reckitt Benckiser Healthcare ltd. UK). Shortly, a lateral 2-3 mm cut was made through the skin, medial to the patella. The patella was displaced to drill through the intercondylar fossa. A stainless steel intramedullary pin ( $17 \mathrm{G}$ and $0.6-0.8 \mathrm{~mm}$ long) was then inserted in the femur towards the great trochanter. Finally, the patella was repositioned and the wound was sutured. Fracture was then performed using a customized three-point fracture apparatus.

\section{Quantitative $\mu$ CT evaluation of fracture callus}

Femurs were collected directly after euthanasia and prepared under binocular where callus size and shape could be clearly distinguished from the surrounding tissue. Intramedullary pins were removed from the femora prior to imaging using ex-vivo $\mu \mathrm{CT}$ imaging system (Viva40 micro-CT, Scanco Medical AG®, Switzerland, $70 \mathrm{kVp}$, $114 \mu \mathrm{A})$. Callus size, geometry, structure and mineralization were characterized at mineralization phases D7 and D10 $(\mathrm{N}=8)$, and at D14 and D21 $(\mathrm{N}=16)$. Fractured and contralateral femora were batch scanned as previously described [24]. Briefly, $10.5 \mu \mathrm{m}$ fixed isotropic voxel size was verified, the scan axis oriented to the femora diaphyseal axis, enclosing the whole fracture callus (VOI). Cortical bone and surrounding tissue were manually contoured; only newly formed tissue was measured with a preset global threshold of $\geq 190 \mathrm{mg} \mathrm{HA} / \mathrm{cm}^{3}$, which is sufficient to exclude muscle tissue. All analyses were performed on the digitally extracted callus tissue using 3D measurements of distances and volumes (Scanco® software, Switzerland).

Assessment of tissue quality by means of ultimate torque and torsional stiffness

Fractured and contralateral femora specimens of D14 and D21 $(\mathrm{N}=8)$ were subjected to biomechanical testing to determine callus stiffness and ultimate torque as described earlier [24]. Briefly, both femur ends were embedded in polymethyl methacrylate (PMMA) resin. Bones were centred using a slot laser, then aligned parallel to the long axis of the torsional testing machine and. After fixation in the torsional testing device, bones were loaded to failure in torsion (parameters: $0.5^{\circ} / \mathrm{s}$ with an axial preload of $0.3 \mathrm{~N}$; using Electro Force 3200 test system, BOSE, USA). All testing was performed under moist conditions to avoid dehydration of the samples. Stiffness and ultimate failure load were extracted and related to the measurements from the contralateral intact bone sample.

\section{Histological analyses}

Histological analyses were conducted on the fractured femora at D7, D10, D14 and D21 post fracture as previously described $[25,26]$. Femora ( $N=8$ per group) were harvested, fixed in 4\% PFA then decalcified (4\% PFA and $14 \%$ EDTA at $4{ }^{\circ} \mathrm{C}$ ). After embedding, paraffin blocks were sectioned in 4- $\mu \mathrm{m}$ slices. Histomorphometry was performed on Movat Pentachrome stained sections as previously described [27].

Sections of femurs embedded in paraffin were used for:

1) Titrate resistant acid phosphatase (TRAP) staining of osteoclasts using following reagents: (Sigma - D4551, N5000, F3381)

2) Immunohistochemistry with following antibodies: rabbit anti osteocalcin (ALX-210-333, Enzo life sciences); rabbit anti factor VIII (CP-039, Biocare Medical); rabbit anti alpha smooth muscle actin (AB5694, Abcam), mouse anti-myosin (F59; DSHB) and mouse anti-Desmin (CM-036, Biocare Medical). TRAP-positive multinuclear cells located on the bone surface were counted as osteoclasts. Osteocalcin positive cells, which are located either on bony structures or within the osteoid, were counted as osteoblasts. Blood vessels were counted in the whole callus sections and were recognized by factor VIII positive cells arranged in a clear vessel formation.

Undecalcified fractured femora D21 $(\mathrm{N}=8)$ were processed and embedded in PMMA according to standard protocols [28]. 6- $\mu \mathrm{m}$
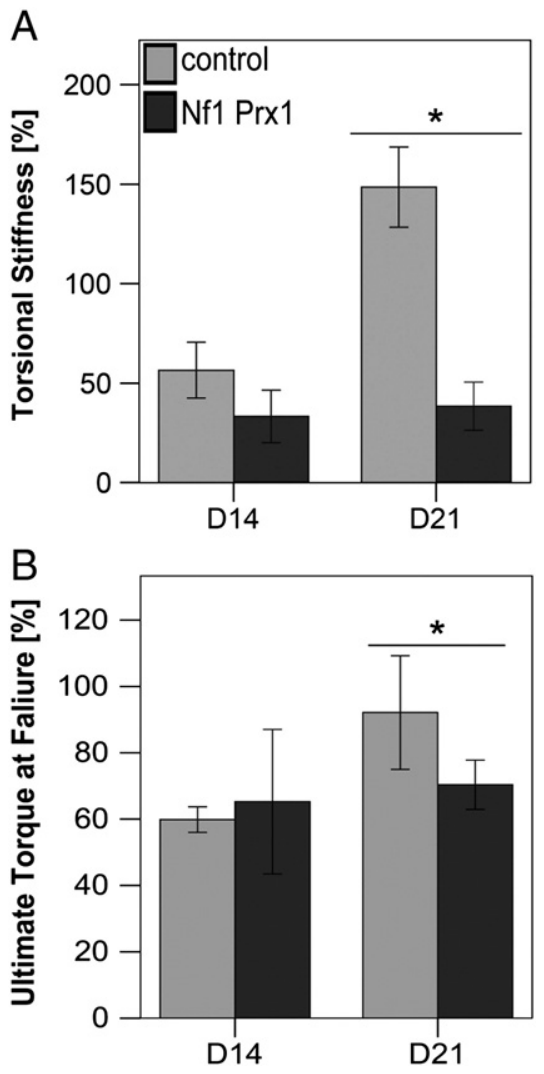

Fig. 2. Mechanical competence of the fracture callus normalized to the mechanical competence of the intact contralateral side at D14 and D21. (A) The torsional stiffness correlates with the level of new bone formation within callus. The fully bridged control callus showed significantly higher torsional stiffness [\%] than non-bridged $\mathrm{Nf1}{ }^{\mathrm{Prx} 1}$ callus at D21. (B) Ultimate torque at failure [\%] reflects biomechanical competence of the healing sites. The control callus showed significantly higher ultimate torque at D21. Both parameters reflect significant decrease of the callus stability in $\mathrm{Nf}^{\mathrm{Prx} 1}$ mice $\left({ }^{*}=\mathrm{p} \leq 0.05\right)$. 
sagittal sections of these fracture callus tissues were stained with Von Kossa/Van Gieson. Evaluation was performed with an image analysis system (KS400 3.0, Zeiss, Germany).

\section{mRNA preparation and expression analysis}

The callus tissue samples were dissected including $1 \mathrm{~mm}$ of healthy cortical bone on either side of the fracture callus $(\mathrm{N}=5)$. The probes were flash frozen in liquid nitrogen and stored at $-80{ }^{\circ} \mathrm{C}$. Tissues were pulverized with pestle and mortar under continuous cooling with liquid nitrogen. After homogenization (T10, Ultraturrax), total RNA was isolated from each sample using TRIzol (Invitrogen Life Technologies, Germany) according to the manufacturer's protocol. DNA was eliminated with DNAse I (Invitrogen Life Technologies). One microgram of total RNA from each sample was then used for quantitative real time polymerase chain reaction.

All reagents for qRT-PCR analysis were purchased from BioRad (iScrip cDNA Synthesis Kit, iQSYBR Green Supermix) and plate assays were read in IQ5 optical software V 2.0 (BioRad, France). RNA quality and quantity was determined spectrophotometrically. One microgram of total RNA was used for CDNA preparation. The DNA amplification was carried out as previously described [29]. In qRT-PCR, samples were run in triplicates. Expression levels were normalized to peptidylprolyl isomerase $A$, also known as cyclophilin A (Cyp A) chosen according to geNorm software. Primers were designed to span exon-intron junction (Qiagen, Germany). Amplicons ranged between 155 and 180 bases with annealing temperature of $62{ }^{\circ} \mathrm{C}$. mRNA expression was calculated with the $\left(2^{-\Delta \mathrm{CT}}\right)$ method to compare relative gene expression at a given time point between the two groups.
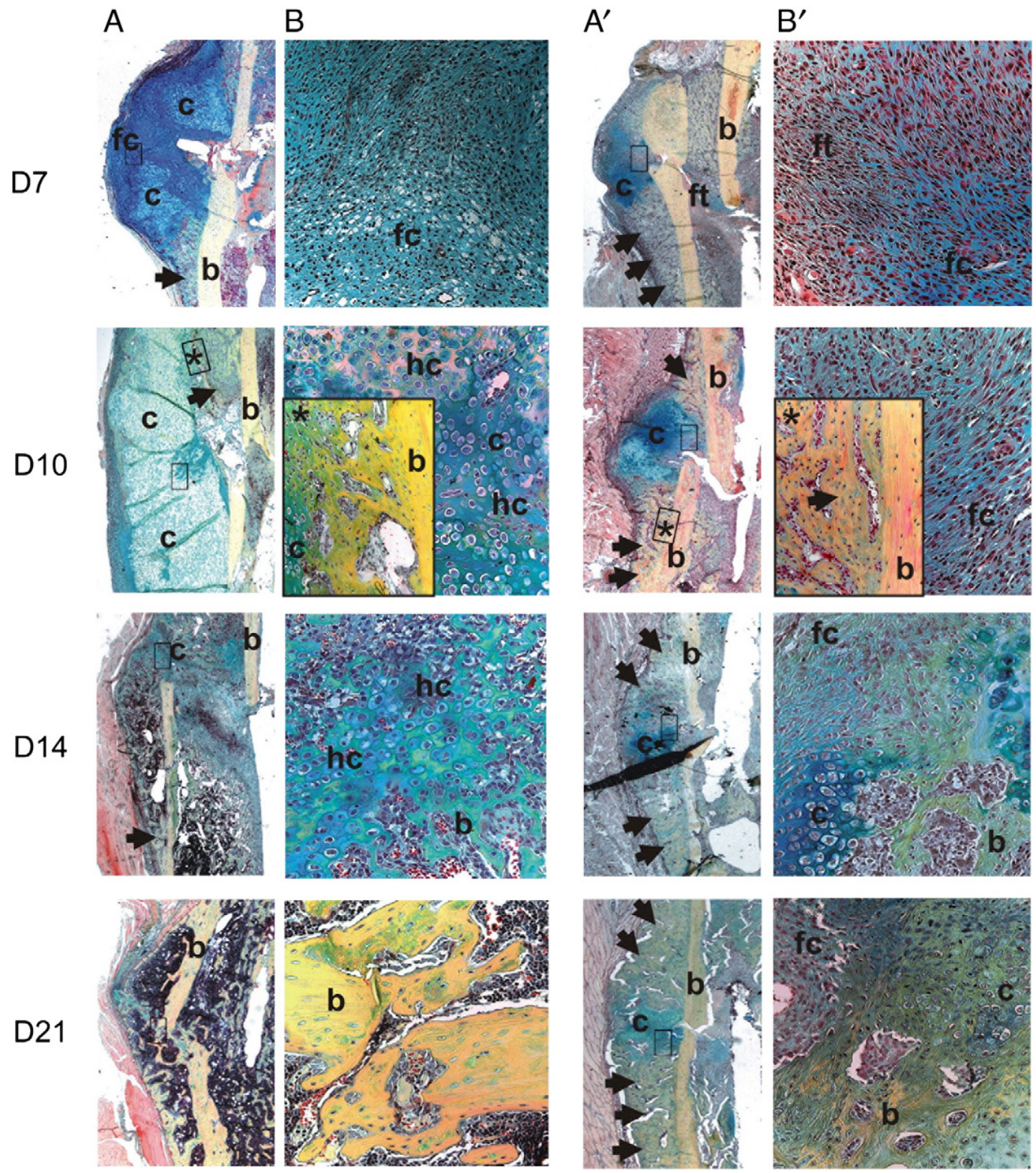

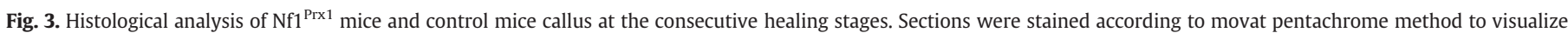

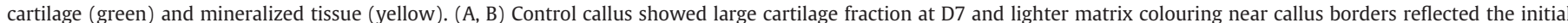

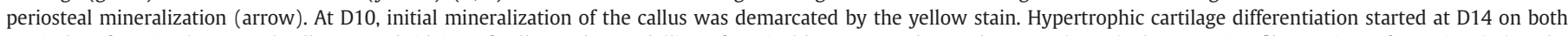

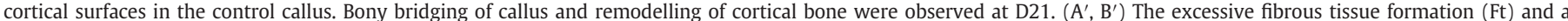

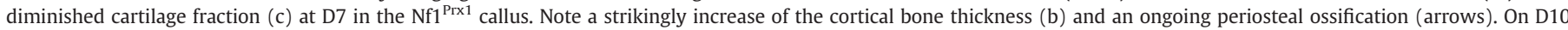

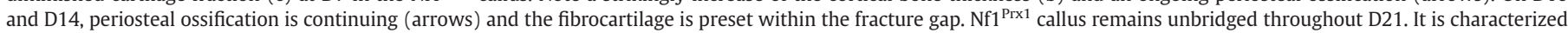
by the thick periosteum and the persistent fibrocartilage within fracture gap. 


\section{Statistical analyses}

Histomorphometry, biomechanics, and $\mu \mathrm{CT}$ as well as qRT-PCR data are exhibited here in graphs as means \pm SEM. Significance testing ran in PASW 18.1 (SPSS Inc., USA) using Mann-Whitney $U$ test for unpaired nonparametric data with Bonferroni correction. Wilcoxon test was performed for osteoid volume evaluation as a non-parametric test used when comparing two repeated measurements. P-values of less than 0.05 were chosen to indicate significance.

\section{Results}

Impaired callus formation in Nf1 $1^{\text {Prx1 }}$ mice

In the $\mu \mathrm{CT}$ data, the Nf1 ${ }^{\mathrm{Prx} 1}$ callus appeared smaller than in the control animals at D14 and D21 (Figs. 1A, B). A representative image of the control mouse fracture at D14 (Fig. 1A-upper panel) shows a large, not yet bridged callus with well-defined areas of mineralized tissue. On D21, control fractures formed a fully bridged, solid bony callus (Fig. 1A-lower panel). In contrast, a representative 3D reconstruction of the $\mathrm{Nf} 1^{\mathrm{Prx} 1}$ fracture at D14 (Fig. 1B-upper panel) depicts a smaller and more compact callus structure. At this stage, an increased bone formation took place near the cortical bone on the periosteum but not in the fracture gap. None of the analyzed Nf1 ${ }^{\text {Prx1 }}$ mice showed bridging by D21 (Fig. 1B-lower panel). In contrast, cortical bone was strikingly thickened, suggesting mineralization of the cortical bone was augmented and/or cortical bone remodelling was defective (Fig. 1B-lower panel).

Regenerative tissue size quantification revealed a progressive increase of the callus size in the control group (Fig. 1C). At D7 and D10 total callus volume (TV) was larger in Nf1 ${ }^{\text {Prx1 }}$ mice than in the control group. As shown by histology, this volume increase was due to rapid initial growth of the fibrous tissue (Fig. 3A). The initial volume increase in $\mathrm{Nf}_{1}{ }^{\text {Prx1 }}$ fractures was reversed at the later stages resulting in significantly smaller callus in the $\mathrm{Nf}^{\mathrm{Prx} 1}$ mice at D14 and D21 ( $\mathrm{p} \leq 0.001$, both; Fig. $1 \mathrm{C}$ ).

Callus bone volume (BV) increased steadily in the consecutive post fracture stages in the control group (Fig. 1D). Interestingly, callus bone volume In Nf1 ${ }^{\text {Prx1 }}$ mice was increased at D7 and D10 as compared to the control group (Fig. D). This effect was caused by desmal type ossification, which took place in the proximity of the cortical bone (Fig. 3A'). At later stages, (D14) callus bone volume ceased to increase in $\mathrm{Nf} 1^{\text {Prx1 }}$ mice and deteriorated at D21. BV/TV ratio in control fractures increased between D10 and reached highest values at D21. In contrast BV/TV in Nf1 ${ }^{\text {Prx1 }}$ group increased between D7 and D10 to reach maximum at D14. At D7 BV/TV was significantly lower in $\mathrm{Nf1}{ }^{\text {Prx1 }}$ mice compared to the control group ( $\mathrm{p} \leq 0.05$ ). At all other time points the BV/TV values were higher in the Nf1 $1^{\operatorname{Prx} 1}$ compared to the control, either in a trend (D10 and D21), or significantly as at $\mathrm{D} 14(\mathrm{p} \leq 0.005)$. As previously mentioned and shown by histological analysis (Fig. 3), this was due to dramatic cortical bone thickening (Fig. 3B'-arrows). Importantly, the callus bone mineral density (BMD) was significantly lower in the $\mathrm{Nf} 1^{\mathrm{Prx} 1}$ mice as compared to controls at all investigated time points ( $\mathrm{p} \leq 0.001$; Fig. $1 \mathrm{E})$.

In order to determine how alteration of callus size and structure affected mechanical properties of the fractured bone, biomechanical testing was performed. In the initial experiments, intact femora were investigated. $\mathrm{Nf} 1^{\mathrm{Prx} 1}$ bones were significantly weaker than the control group femora ( $\mathrm{p} \leq 0.01$, for both torsional stiffness and ultimate torque at failure - data not shown). To account for this intrinsic difference, biomechanical testing results from the fractured femora were normalized against results obtained from the intact, contralateral femora of the same mouse. With this setup $\mathrm{Nf1}{ }^{\text {Prx1 }}$ group at D21 displayed a significantly lower torsional stiffness $(\mathrm{p} \leq 0.05$; Fig. 2A). Additionally, lower ultimate torque at failure was seen at D21 ( $\mathrm{p} \leq 0.01$; Fig. 2B). At D14, Nf1 ${ }^{\operatorname{Prx} 1}$ fractures showed a lower torsional stiffness trend. This lower biomechanical competence documents qualitative deterioration or delay of the fracture repair and an inferior functional recovery in the $\mathrm{Nf} 1^{\mathrm{Prx} 1}$ mice.

Impaired cartilage formation and increased periosteal ossification in the Nf1 ${ }^{\text {Prx1 }}$ fractures

Histomorphometric analysis was performed on movat pentachrome stained sections. We quantified dimensions and distribution of the callus cartilage fraction (blue-green stain) and the callus periosteal surface area (yellow stain).

At D7, the control group displayed a large cartilaginous callus with periosteal ossification starting adjacent to the cartilage borders. At D10, control callus matrix displayed yellow staining in the periosteal regions reflecting progressing matrix mineralization. Patches of hypertrophic cartilage differentiation were present throughout the control callus tissue at D14 and ossification (indirectly detected as yellow staining) took place on both cortical sides at this stage. At D21, the control callus was fully bridged and cortical bone largely remodelled (Fig. 3A).

Compared to the normal fracture repair process, formation of the cartilaginous callus in the $\mathrm{Nf1}{ }^{\mathrm{Prx} 1}$ mice was severely diminished. Only a small and weakly stained cartilaginous rudiment was formed by D7. At this stage, the fracture gap in the Nf1 ${ }^{\text {Prx1 }}$ callus was filled with fibrous tissue (Fig. 3A). Defective cartilage formation was accompanied
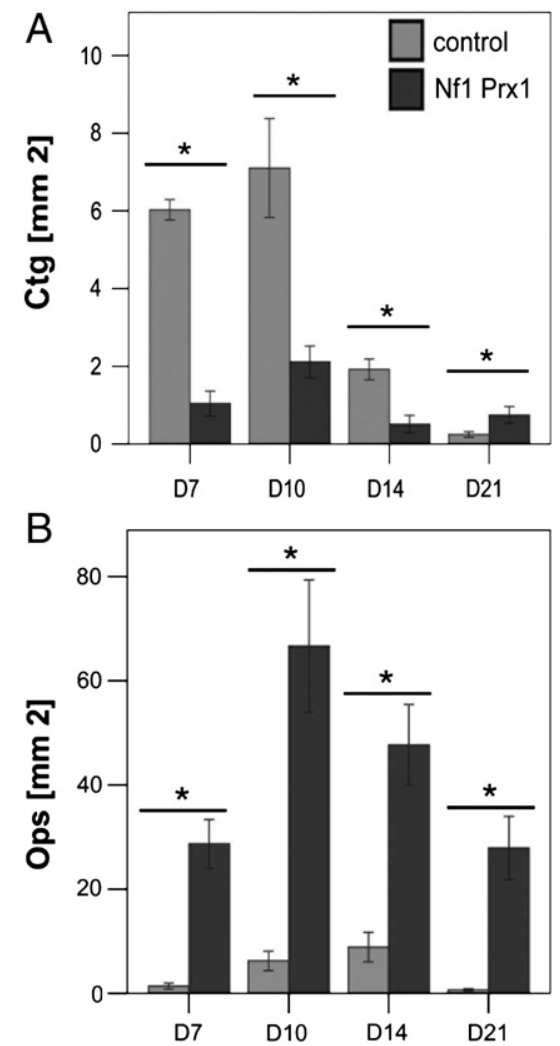

Fig. 4. Histomorphometric quantification of cartilage fraction (Cgt) and periosteal surface ossification (Ops) at the consecutive stages post fracture. (A) Due to hypertrophy and mineralized tissue formation a continuous decline of cartilage fraction during healing process was observed in the control callus. Nf1 ${ }^{\text {Prx1 }}$ callus shows smaller cartilage fraction on both D7 and D14 compared to control. Higher cartilage fraction value on D21 in Nf1 ${ }^{\text {Prx1 }}$ mice as compared to controls reflects persistence of the fibro cartilage in the fracture gap $\left({ }^{*}=p \leq 0.05\right)$. (B) In the control mice, periosteal surface size reached peak at D14 and was reduced at D21 due to remodelling. In $\mathrm{Nf}^{\mathrm{Prx} 1}{ }^{\text {, mice peri- }}$ osteal surface was dramatically increased as compared to controls $\left({ }^{*}=\mathrm{p} \leq 0.01\right.$ at all analyzed stages). 
by intense cortical ossification on both periosteal and endosteal cortical bone surfaces. This ossification did not significantly contribute to the overall repair process as it occurred distant to the fracture gap (Fig. 3B'). Periosteal bone formation was more evident at D10. At this time point, a thick layer of newly formed bone covered cortical bone (Fig. 3B'-arrows). This was also observed at D14, where a thicker periosteal ossification was accompanied by the presence of fibrous tissues in the fracture gap. Irregularly distributed and scarce hypertrophic cartilage zones were observed at this stage and persisted throughout D21 in callus of $\mathrm{Nf}^{\mathrm{Prx} 1}$ mice. Importantly, at D21 the $\mathrm{Nf} 1^{\mathrm{Prx} 1}$ callus was dominated by fibrous tissue zones. Only at the cortices, a thickened layer of periostealy formed bone was visible which did not lead to bridging of the gap (Fig. 3A').

We quantified the surface of the cartilage tissue (Ctg) and the ossified periosteal bone surface (Ops) in the callus using morphometric analysis. The callus cartilage fraction in the control group was highest at D10 and declined thereafter over time (Fig. 4A). Compared to controls, the Nf1 $1^{\text {Prx1 }}$ callus cartilage fraction was smaller, by $90 \%$ at $\mathrm{D} 7$, by $70 \%$ at $\mathrm{D} 10$ and by $75 \%$ at $\mathrm{D} 14$. These proportions were inverted at D21, at which time in the control mice most of the callus cartilage was replaced with the newly formed bone, whereas cartilage persisted in the $\mathrm{Nf}_{1} 1^{\mathrm{Prx} 1}$ mice (Fig. 4A). Thus, compared to the control group, the $\mathrm{Nf} 1^{\text {Prx1 }}$ group showed lower callus cartilage surface at D7, D10 and D14 ( $\mathrm{p} \leq 0.01)$ and a higher values at D21 ( $\leq 0.05)$. In control mice, ossified periosteal bone surface (Ops) reached a peak at D14 and declined thereafter (D21), likely due to remodelling processes. The Ops was significantly increased in the Nf1 ${ }^{\operatorname{Prx} 1}$ mice compared to control mice at all tested time points ( $\mathrm{p} \leq 0.01$ at all time points; Fig. 4B).
Thus, Nf1 ${ }^{\operatorname{Prx} 1}$ mice showed a delay in fracture healing which was characterized histologically by a diminished initial cartilaginous callus formation and persistence of cartilage at D21. These changes were accompanied by increased periosteal ossification, but bridging was not achieved within 21 days post fracture.

Increased number of osteoblasts and vessels in Nf1 $1^{\text {Prx1 }}$ callus

Since histological analysis suggested that bone formation was differentially affected in cortical bone vs. cartilaginous callus in $\mathrm{Nf} 1^{\operatorname{Prx} 1}$ mice, osteocalcin positive osteoblasts were quantified within the fracture gap and at the periosteal surface of the callus. In line with the histomorphometric results, fewer osteoblasts were detected within the fracture gap in $\mathrm{Nf1}{ }^{\text {Prx1 }}$ mice throughout the healing process ( $p \leq 0.05$, Fig. $5 \mathrm{~A}$ ). However, osteoblast number was significantly increased at the periosteal surface in $\mathrm{Nf}^{\mathrm{Prx} 1}$ mice at all analyzed time points ( $p \leq 0.05$, Figs. $5 B$ and $C$ ). Additionally, the presence of large areas of non-mineralized osteoid $(\mathrm{OV} / \mathrm{BV}$, control $=0.21 \pm 0.017$; $\mathrm{Nf} 1^{\mathrm{Prx} 1}=2.9 \pm 0.81$ ) in the fracture gap of $\mathrm{Nf} 1^{\operatorname{Prx} 1}$. This reflects a decreased mineralization of the extracellular matrix, thus hinting to an impaired osteoblasts capability to mineralize the matrix. Thickening of the osteoid layer was also apparent in the periosteal region (data not shown). These data further support the notion that endochondral bone formation is impaired in Nf1 ${ }^{\text {Prx1 }}$ mice but periosteal bone formation is enhanced (Fig. 5F).

The analysis of callus vascularization (vessel density in fibrous tissue) using vessel specific factor VIII staining showed a significantly increased number of blood vessels in the Nf1 ${ }^{\text {Prx1 }}$ fractures compared to controls at all time points ( $\mathrm{p} \leq 0.05$, Figs. $5 \mathrm{E}$ and $\mathrm{F})$.
A
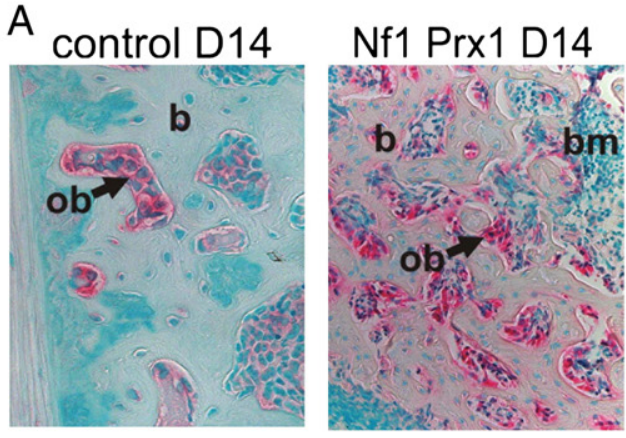

B

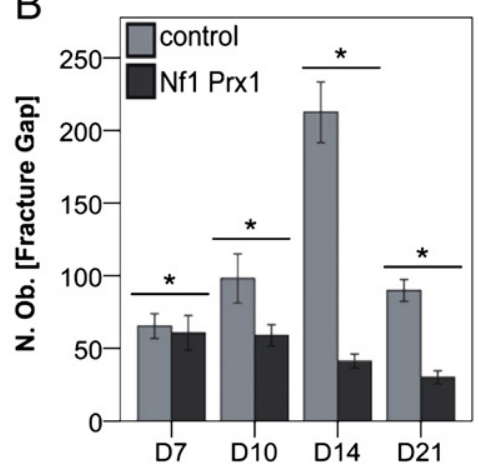

E

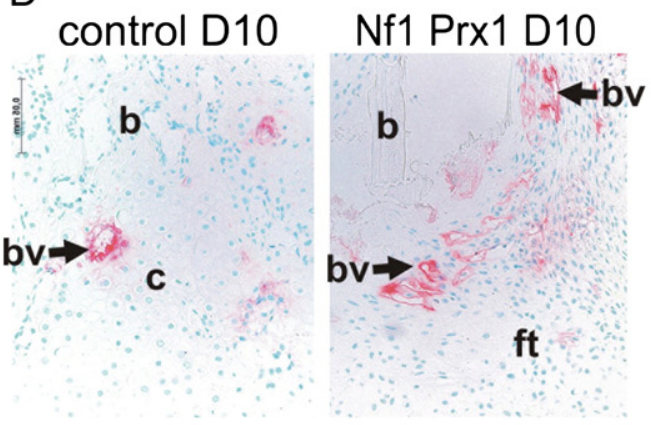

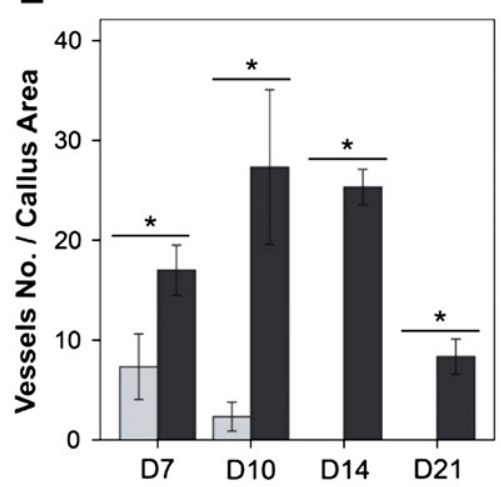

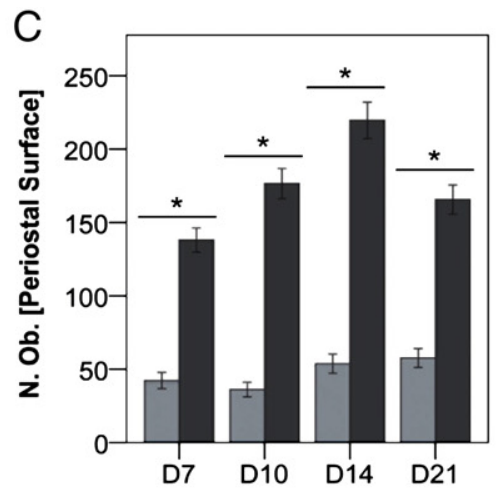

$\mathrm{F}$

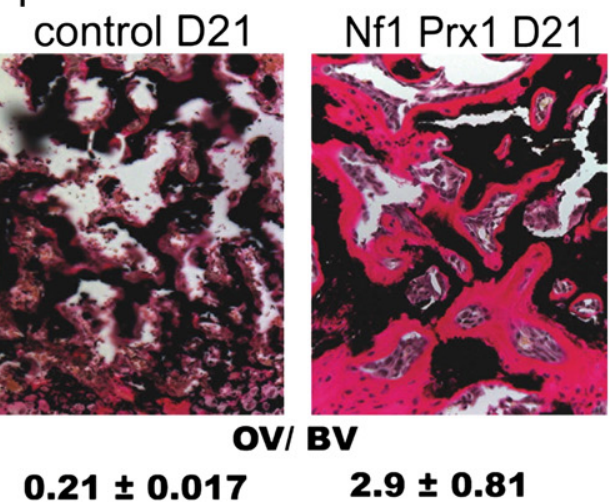

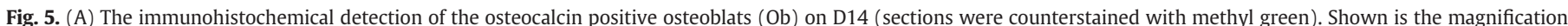

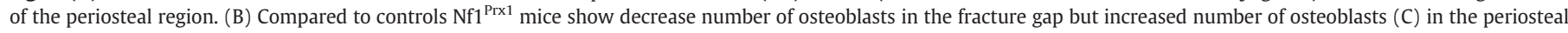

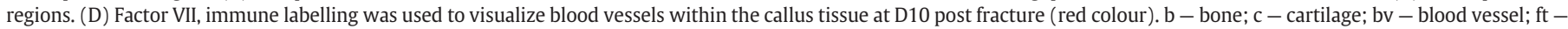

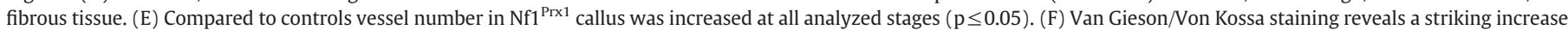

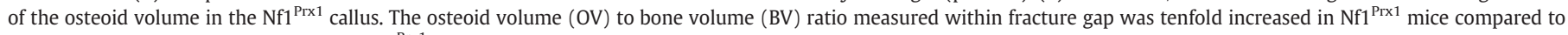
controls $\left(\mathrm{OV} / \mathrm{BV}\right.$, control $\left.=0.21 \pm 0.017 ; \mathrm{Nf}^{\mathrm{Prx} 1}=2.9 \pm 0.81, \mathrm{p} \leq 0.05\right)$. 
Increased number of osteoclasts in Nf1 ${ }^{\text {Prx1 }}$ callus

In order to quantify osteoclasts, bone sections were stained for tartrate resistant acid phosphatase (TRAP) activity. Multinucleated TRAP positive cells were more abundant in the $\mathrm{Nf}^{\mathrm{Prx} 1}$ callus than in control tissue starting with D10 (Figs. $6 \mathrm{~A}$ and $\mathrm{B}, \mathrm{p} \leq 0.05$ ). Intriguingly, most of the TRAP positive cells in the Nf1 ${ }^{\operatorname{Prx} 1}$ callus appeared to be localized within fibrous tissue and not on the bone surface as in the control mice (Fig. 6A). These data suggest that in Nf1 ${ }^{\text {Prx1 }}$ callus, osteoclasts which do not have direct contact with the bone surface, will not participate in bone remodelling.

Smooth muscle actin positive myofibroblasts in the fracture gap in Nf1 ${ }^{\text {Prx } 1}$ mice

Smooth muscle alpha actin ( $\alpha$ SMA) is produced in myofibroblasts, which exhibit contractile properties. Myofibroblasts are cells of yet uncertain origin. They are implicated in skin wound healing and Keloid disease, which is characterized by non-cartilagious, benign fibrous nodule formation [30,31]. Immunohistological staining on control specimen revealed $\alpha$ SMA positive cells in the fracture fibrous tissue and in the bone marrow space at D7 and to a lesser degree at D10 and D14. However, these cells were no longer detected at D21 in the control callus (Figs. 7A, and $\mathrm{A}^{\prime}$ ). In the Nf1 ${ }^{\text {Prx1 }}$ mice, $\alpha$ SMA positive cells were abundantly present in the fracture gap at D7 and D10 and could still be detected throughout D21. Clearly, myofibroblasts constitute a prominent cell population within the fibrous tissue in the fracture gap in $\mathrm{Nf}^{\mathrm{Prx} 1}$ mice (Figs. 7B, and $\mathrm{B}^{\prime}$ ).

\section{Discussion}

Deterioration of bone quality, fracture and abnormal repair processes resulting in pseudarthrosis are a major source of morbidity in NF1 patient. The present study investigates fracture healing process in femoral bones of the Nf1 ${ }^{\operatorname{Prx} 1}$ mice, bearing conditional inactivation of the $N f 1$ gene in the limbs [11]. Femoral bone fractures were analyzed, as tibia bowing in Nf1 ${ }^{\text {Prx1 }}$ mice precluded fracture fixation with intramedulary canal pin.

Major histological findings of this study are: a) diminished cartilaginous callus formation in $\mathrm{Nf1}{ }^{\mathrm{Prx} 1}$ mice; b) increased periosteal bone formation in the fractured $\mathrm{Nf} 1^{\mathrm{Prx} 1}$ cortical bone; c) accumulation and persistence of the fibrous tissue in the Nf1 ${ }^{\text {Prx1 }}$ fracture gap, with the abundant incidence of $\alpha$ SMA positive myofibroblasts and TRAP positive osteoclasts. Histomorphometric analysis, $\mu \mathrm{CT}$ evaluation, as well as mechanical testing revealed that none of the analysed $\mathrm{Nf} 1^{\mathrm{Prx} 1}$ mice achieved bony bridging within 21 days post fracture, yielding mechanically unstable fractures reminiscent of the pseudarthrosis observed in NF1 patients (Figs. 1 and 2).

The maximum torque at failure and the torsional stiffness of the fracture site at D21 were significantly decreased in Nf1 ${ }^{\operatorname{Prx} 1}$ mice (Fig. 2). This was clearly a more dramatic effect then the one reported in the mice bearing conditional Nf1 ablation in osteoblastic lineage $\left(N f 1^{-/-}{ }_{o b}\right)$ where only maximum force parameter was reduced at D28 [10]. The primary cause of the observed deterioration of fracture healing was a failure to form a cartilaginous callus and a concomitant fibrous tissue accumulation (Fig. 3). This phenomenon has not been observed in $\mathrm{Nf1}^{-/-}{ }_{o b}$ mice where callus size and bone formation were both increased [10]. These data collectively show that Nf1

A

control D14

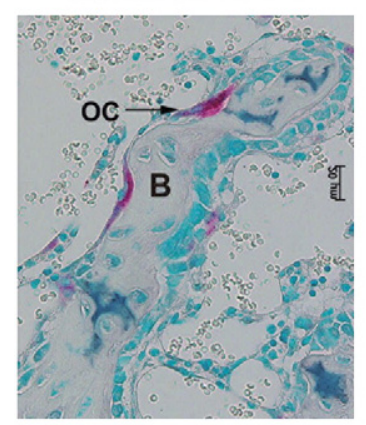

Nf1 Prx1 D14

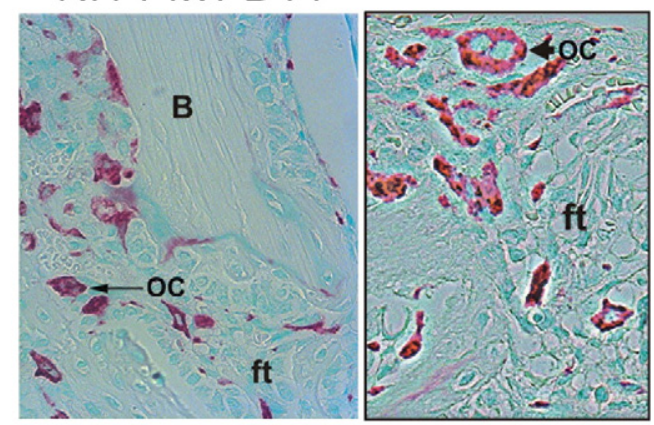

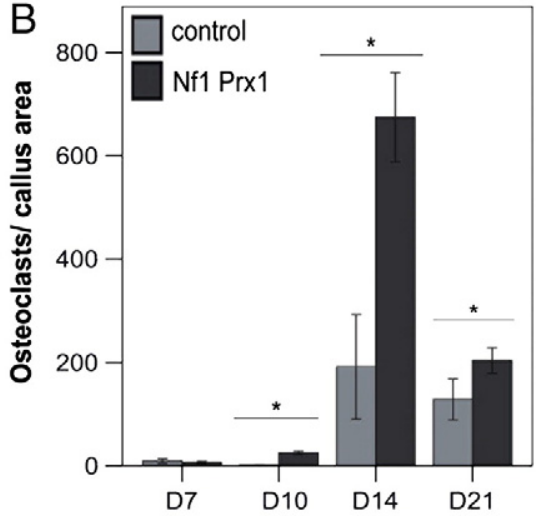

D

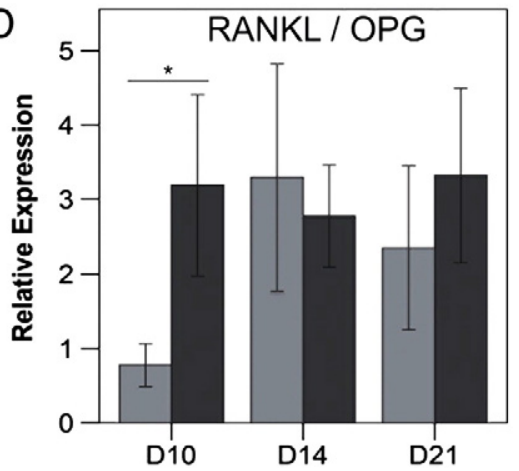

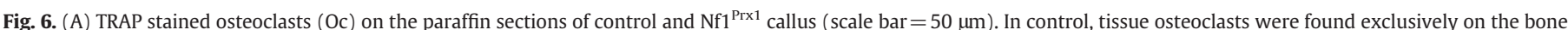

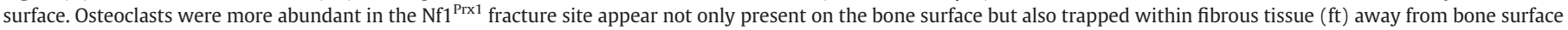

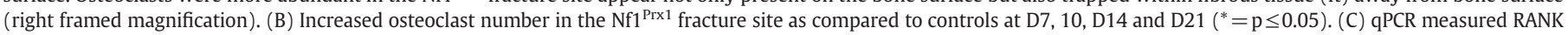
ligand (RANKL) expression and RANKL/OPG ratio in the $\mathrm{Nf}^{\mathrm{Prx} 1}$ fracture compared to control tissue at D10, D14, and D21. 


\section{$\alpha$-smooth muscle actin myosin \\ DAPI}

A

D7
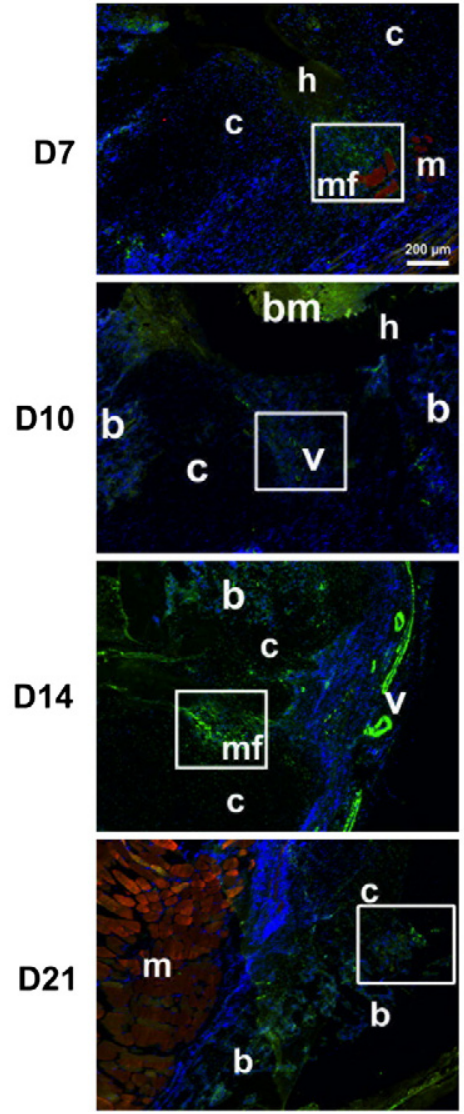

B

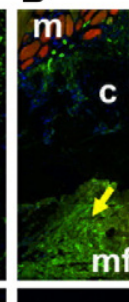

NF1 Prx1

$A^{\prime}$
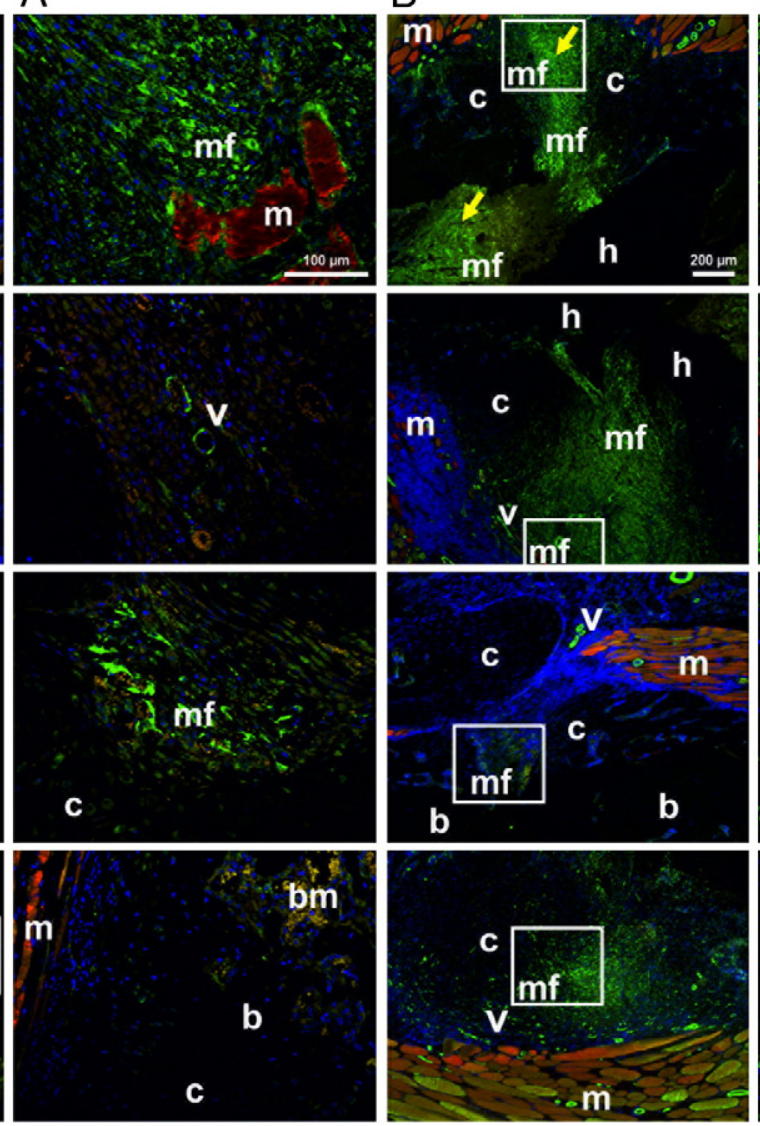
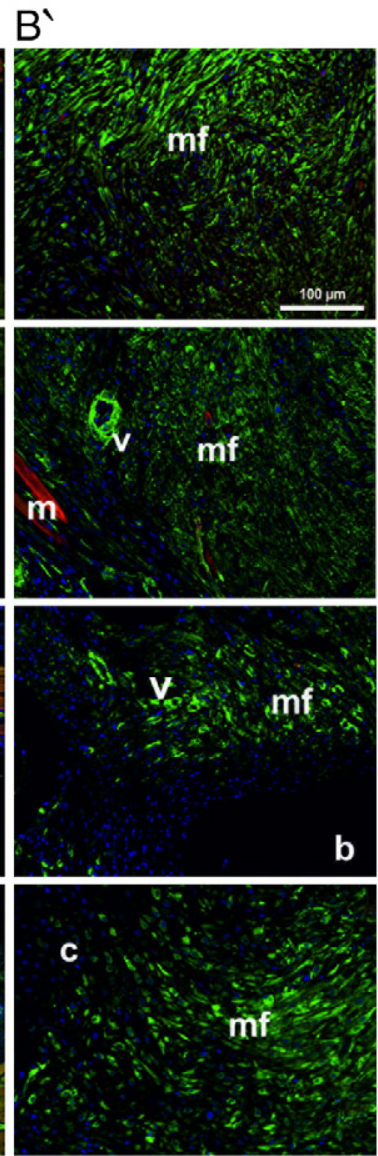

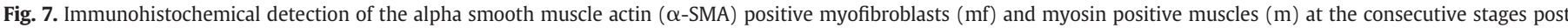

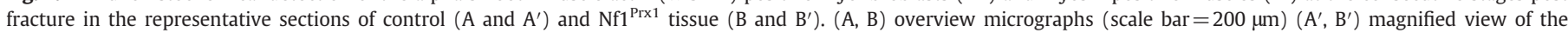

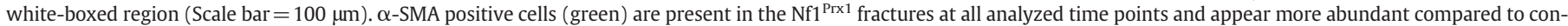

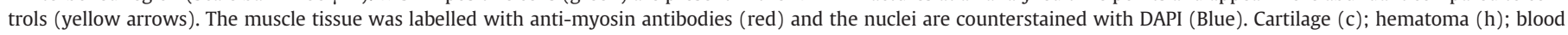
vessels (v); bone (b).

inactivation in the limb mesenchymal progenitors - but not inactivation restricted to the bone lineage - is sufficient to cause non-healing fractures with significantly reduced tissue competence. Most recently, local Nf1 gene inactivation via adenoviral Cre recombinase delivery has shown to be sufficient to delay fracture bridging and to induce fibrous tissue growth [13]. However, increased periosteal bone formation was not reported in any of NF1 mouse models to date. This unique feature was recapitulated in the current study in $\mathrm{Nf} 1^{\text {Prx1 }}$ mice where histological and $\mu \mathrm{CT}$ analysis at D7 revealed increased desmal ossification at the periosteal surface of cortical bone (increased BV in mutant callus at D7 was a result of it).

Interestingly, such thickening of the cortical bone and narrowing of the medullar cavity were shown to characterise anterolaterally bowed tibia in NF1 patients [7]. The observed induction of the perisosteal bone formation in the $\mathrm{Nf}^{\mathrm{Prx} 1}$ fracture model mirrors this phenotype. This observation appears also consistent with the reported differential effect of $N f 1$ gene inactivation depending on the stage of osteoblast maturity, where early inactivation inhibits differentiation and late stage inactivation exerts an opposite effect [13]. In line with this, while the mesenchymal progenitor differentiation and callus formation are strikingly inhibited in the $\mathrm{Nf} 1^{\mathrm{Prx} 1}$ mice, the periosteal (mature) osteoblasts produce more bone (Figs. 1 and 4). Bone formation was also accelerated in $\mathrm{Nf1}^{-/-}{ }_{o b}$ callus but the cortical bone thickening was not observed in this model [10], suggesting that in addition to Nf1 inactivation in bone, extra-osseous tissue inactivation is required to induce periosteal bone formation.

Both the Nf1 ${ }^{\operatorname{Prx} 1}$ and $\mathrm{Nf} 1^{-/-}{ }_{o b}$ mice showed increased osteoid surface, increased expression of RANKL and an associated increased number of osteoclasts (Figs. 5 and 6) [10]. In $\mathrm{Nf1}^{-1-}$ ob mice osteoclasts appeared to be predominantly in contact with the abundant trabecular bone [10]. In the Nf1 ${ }^{\operatorname{Prx} 1}$ mice as well as in the local inactivation model [13], osteoclasts were not only restricted to bone surface but also present within fibrous tissue, suggesting that their subpopulation does not participate in remodelling (Fig. 6A). Nevertheless, observed reduction of the bone mineral density (BMD) in $\mathrm{Nf} 1^{\mathrm{Prx} 1}$ mice appears to be directly linked with the increased osteoclast number (Fig. 1E).

As mentioned, diminished cartilage formation is likely a primary cause of fracture healing deterioration in Nf1 ${ }^{\mathrm{Prx} 1}$ mice (Fig. 3 ). The origins of the normal callus cartilage cells as well as fibrous tissue in Nf1 ${ }^{\text {Prx } 1}$ remain elusive. It is currently believed that callus formation recapitulates the process of embryonic cartilage formation. However, presented here data from Nf1 $1^{\mathrm{Prx} 1}$ model analyses suggest that this might be an oversimplified theory. In Nf1 ${ }^{\operatorname{Prx} 1}$ mice, Nf1 is inactivated in the early limb bud mesenchyme, but embryonic cartilage formation is not delayed [11]. On the contrary, callus cartilage formation is severely impaired in Nf1 $1^{\operatorname{Prx} 1}$ bone healing. Additionally, capability of the formed cartilage to hypertrophy and mineralize was strongly 
reduced as revealed by decreased type $\mathrm{X}$ collagen (ColX) expression (Supplemental Fig. 1). Thus, the source and the nature of the mesenchymal progenitor cells or the signalling milieu in which cartilage commitment occurs must be profoundly different in the embryonic and in the callus tissue in the $\mathrm{Nf} 1^{\mathrm{Prx} 1}$ model. These observations are of likely importance to bone regeneration research beyond NF1 studies. Implications for delayed healing in normal fractures should be considered and a change of paradigm might be needed once we understand in more detail the exact differences between embryonic and callus cartilage formation process.

Adequate callus vascularization is required for normal fracture healing [32] and it is recognized that the endothelium derived cells can contribute to osteogenesis in the process of endothelial to mesenchymal transformation [33. Pathological activation of this process is associated with fibrodysplasia ossificans progressiva (FOP) resulting in ectopic bone formation [33]. Lineage tracing experiments in the bone fractures indicate that $\alpha \mathrm{SMA}$ expressing cells originate from perivascular cells and have potential to differentiate to chondrocytes, osteoblasts and osteocytes [34]. In Nf1 ${ }^{\text {Prx1 }}$ mice, although vascularization of the fracture tissue was increased, no osteogenesis resulted. Instead, we observed accumulation of the smooth muscle actin positive myofibroblasts (Figs. 7A, B). These cells were also previously reported to be present in the congenital pseudarthrosis in NF1 patients [35]. The vascular origin of these cells is likely and their presence points to a possible role of the TGF $\beta$ signalling in the deterioration of bone fracture healing in Nf $1^{\operatorname{Prx} 1}$ mice as myofibroblastic differentiation is known to depend on this signalling pathway [36].

Following the initial fibrous tissue accumulation phase at D7, Collagen I expression became less abundant at D10, D14, and D21 in the $\mathrm{Nf} 1^{\mathrm{Prx} 1}$ fractures compared to controls, as detected by qPCR
(Supplemental Fig. 1). Type III collagen was found to be the major type of collagen in human non-unions [37]. In line with that, we detected increased expression of type III Collagen in the fracture site in Nf1 ${ }^{\text {Prx1 }}$ mice using microarray transcriptional profiling (data not shown - in preparation for a separate manuscript).

Additionally, histological analysis yielded further intriguing observations (Fig. 8).

1) Ectopic fat tissue was observed in fracture site and within muscles in $\mathrm{Nf} 1^{\mathrm{Prx} 1}$ mice (Fig. 8A-blue arrows). This observation was also previously made in the context of NF1 pseudarthrosis [38,39], suggesting that the absence of $N f 1$ affects fat cell differentiation and/or proliferation.

2) A continuous 'stream' of collagen producing fibroblast-like cells, appeared to originate from the muscles at the direct proximity to the fracture gap (Fig. 8A, B-red arrows). This tissue did not stain positive for Desmin (Fig. 8B) and was of similar histological appearance to fascia tissue within Nf1 ${ }^{\operatorname{Prx} 1}$ muscle prior to injury. Based on this it seems possible that the muscle connective tissue might, at least in part, be a source of the fibrous tissue within the fracture site of $\mathrm{Nf} 1^{\text {Prx } 1}$ mice. Cell lineage tracing experiments are required to determine the exact nature and the developmental origin of these cells.

Collectively, we have shown that in the Nf1 ${ }^{\text {Prx1 }}$ mice both developmental processes leading to the long bone dysplasia and the subsequent fracture healing deterioration closely resemble NF1 tibial dysplasia and pseudarthrosis (development of a non-union after a fracture). Presented fracture model will be useful for pre-clinical studies aimed at pharmacological interventions targeting deteriorating fracture-healing process in the NF1 tibial dysplasia.
A

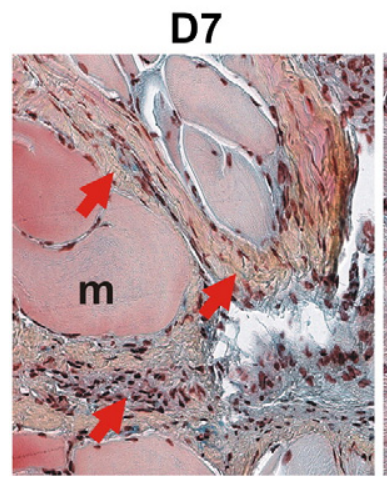

B fracture

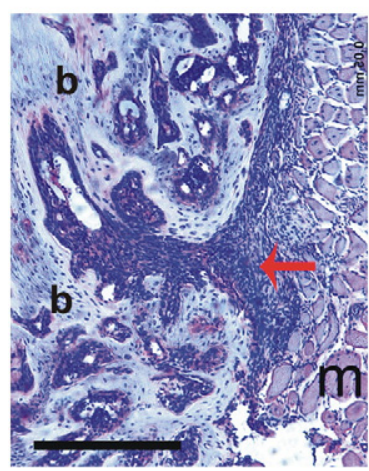

Nf1Prx1
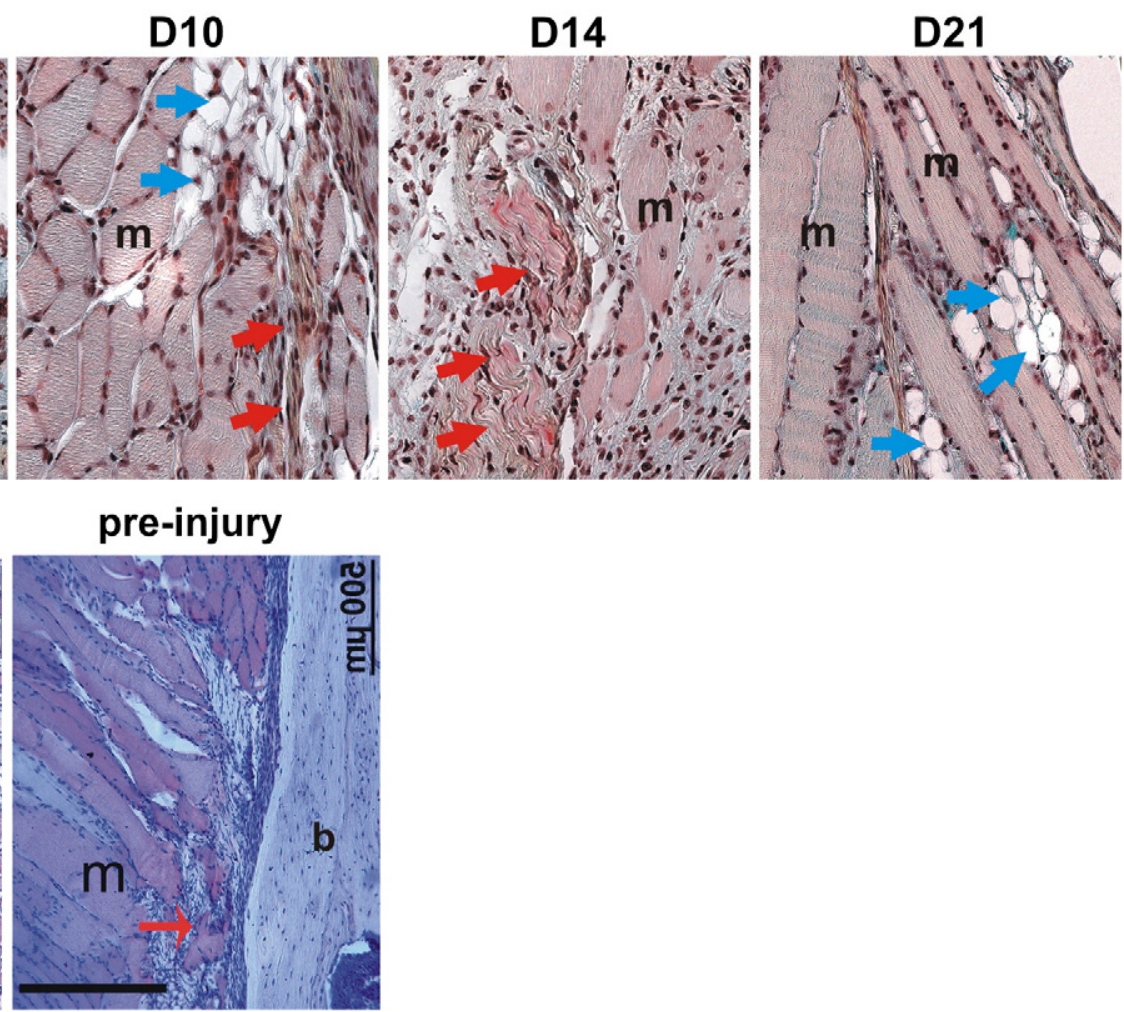

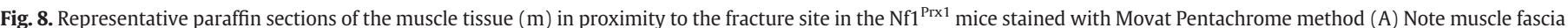

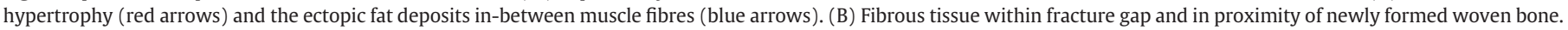

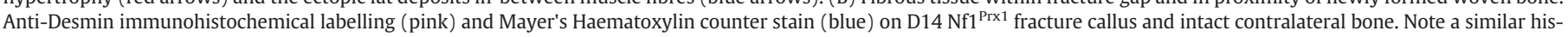
tological appearance of the femur fascia cells before the injury and the fibrous tissue cells within fracture site. $(\mathrm{m}=\mathrm{muscle}, \mathrm{b}=$ bone, scale bare $=500 u \mathrm{~m}, \mathrm{~N}=4$ ). 
Supplementary data to this article can be found online at http:// dx.doi.org/10.1016/j.bone.2012.07.011.

\section{Acknowledgments}

This study was in part supported by the Berlin Brandenburg Center for Regenerative Therapies (BCRT). TE was supported by the Berlin Brandenburg School for Regenerative Therapies (BSRT). The study was also supported by the grant NF1-01GM0844 from Bundesministerium für Bildung und Forschung (BMBF). We thank Monika Osswald and Carola Dietrich for excellent technical assistance.

\section{References}

[1] Ferguson C, Alpern E, Miclau T, Helms JA. Does adult fracture repair recapitulate embryonic skeletal formation? Mech Dev 1999;87:57-66.

[2] Ippolito E, Corsi A, Grill F, Wientroub S, Bianco P. Pathology of bone lesions associated with congenital pseudarthrosis of the leg. J Pediatr Orthop B 2000;9:3-10.

[3] Alwan S, Armstrong L, Joe H, Birch PH, Szudek J, Friedman JM. Associations of osseous abnormalities in Neurofibromatosis 1. Am J Med Genet A 2007;143A:1326-33.

[4] Stevenson DA, Birch PH, Friedman JM, Viskochil DH, Balestrazzi P, Boni S, et al. Descriptive analysis of tibial pseudarthrosis in patients with neurofibromatosis 1. Am J Med Genet 1999;84:413-9.

[5] Vitale MG, Guha A, Skaggs DL, Vitale MG, Guha A, Skaggs DL. Orthopaedic manifestations of neurofibromatosis in children: an update. Clin Orthop Relat Res 2002:107-18.

[6] Serra E, Ars E, Ravella A, Sanchez A, Puig S, Rosenbaum T, et al. Somatic NF1 mutational spectrum in benign neurofibromas: mRNA splice defects are common among point mutations. Hum Genet 2001;108:416-29.

[7] Stevenson DA, Zhou H, Ashrafi S, Messiaen LM, Carey JC, D'Astous JL, et al. Double inactivation of NF1 in tibial pseudarthrosis. Am J Hum Genet 2006;79:143-8.

[8] Brannan CI, Perkins AS, Vogel KS, Ratner N, Nordlund ML, Reid SW, et al. Targeted disruption of the neurofibromatosis type-1 gene leads to developmental abnormalities in heart and various neural crest-derived tissues. Genes Dev 1994;8:1019-29.

[9] Schindeler A, Morse A, Harry L, Godfrey C, Mikulec K, McDonald M, et al. Models of tibial fracture healing in normal and Nf1-deficient mice. J Orthop Res 2008;26: 1053-60.

[10] Wang W, Nyman JS, Moss HE, Gutierrez G, Mundy GR, Yang X, et al. Local low-dose lovastatin delivery improves the bone-healing defect caused by Nf1 loss of function in osteoblasts. J Bone Miner Res 2010;25:1658-67.

[11] Kolanczyk M, Kossler N, Kuhnisch J, Lavitas L, Stricker S, Wilkening U, et al. Multiple roles for neurofibromin in skeletal development and growth. Hum Mol Genet 2007; 16:874-86.

[12] Wu X, Chen S, He Y, Rhodes SD, Mohammad KS, Li X, et al. The haploinsufficient hematopoietic microenvironment is critical to the pathological fracture repair in murine models of neurofibromatosis type 1. PLoS One 2011;6:e24917.

[13] El-Hoss J, Sullivan K, Cheng T, Yu NYC, Bobyn JD, Peacock L, et al. A murine model of neurofibromatosis type 1 tibial pseudarthrosis featuring proliferative fibrous tissue and osteoclast-like cells. J Bone Miner Res 2012;27:68-78.

[14] Yu X, Chen S, Potter OL, Murthy SM, Li J, Pulcini JM, et al. Neurofibromin and its inactivation of Ras are prerequisites for osteoblast functioning. Bone 2005;36: 793-802.

[15] Yan J, Chen S, Zhang Y, Li X, Li Y, Wu X, et al. Rac1 mediates the osteoclast gainsin-function induced by haploinsufficiency of Nf1. Hum Mol Genet 2008;17:936-48.

[16] Yang FC, Chen S, Robling AG, Yu X, Nebesio TD, Yan J, et al. Hyperactivation of p21ras and PI3K cooperate to alter murine and human neurofibromatosis type 1-haploinsufficient osteoclast functions. J Clin Invest 2006;116:2880-91.
[17] Kuorilehto T, Kinnunen P, Nissinen M, Alanne M, Leskela HV, Lehenkari P, et al. Vasculopathy in two cases of NF1-related congenital pseudarthrosis. Pathol Res Pract 2006;202:687-90.

[18] Lasater EA, Bessler WK, Mead LE, Horn WE, Clapp DW, Conway SJ, et al. Nf1+/mice have increased neointima formation via hyperactivation of a Gleevec sensitive molecular pathway. Hum Mol Genet 2008;17:2336-44.

[19] Lehrnbecher T, Gassel AM, Rauh V, Kirchner T, Huppertz HI. Neurofibromatosis presenting as a severe systemic vasculopathy. Eur J Pediatr 1994;153:107-9.

[20] Kossler N, Stricker S, Rodelsperger C, Robinson PN, Kim J, Dietrich C, et al Neurofibromin (Nf1) is required for skeletal muscle development. Hum Mol Genet 2011;587(20):2697-709.

[21] Kolanczyk M, Kuhnisch J, Kossler N, Osswald M, Stumpp S, Thurisch B, et al Modelling neurofibromatosis type 1 tibial dysplasia and its treatment with lovastatin. BMC Med 2008;6:21.

[22] Oni OO, Stafford H, Gregg PJ. A study of diaphyseal fracture repair using tissue isolation techniques. Injury 1992;23:467-70.

[23] Bonnarens F, Einhorn TA. Production of a standard closed fracture in laboratory animal bone. J Orthop Res 1984;2:97-101.

[24] Toben D, Schroeder I, El Khassawna T, Mehta M, Hoffmann JE, Frisch JT, et al. Fracture healing is accelerated in the absence of the adaptive immune system. J Bone Miner Res 2011;26:113-24.

[25] Gerstenfeld LC, Wronski T], Hollinger JO, Einhorn TA. Application of histomorphometric methods to the study of bone repair. J Bone Miner Res 2005;20:1715-22.

[26] Parfitt AM, Drezner MK, Glorieux FH, Kanis JA, Malluche H, Meunier PJ, et al. Bone histomorphometry: standardization of nomenclature, symbols, and units. Report of the ASBMR Histomorphometry Nomenclature Committee. J Bone Miner Res 1987;2:595-610.

[27] Peters A, Toben D, Lienau J, Schell H, Bail HJ, Matziolis G, et al. Locally applied osteogenic pre-differentiated progenitor cells are more effective than undifferentiated mesenchymal stem cells in the treatment of delayed bone healing. Tissue Eng Part A 2009; 15:2947-54.

[28] Kenner GH, Hendricks L, Gimenez G, Barb W, Park JB. Bone embedding technique with inhibited PMMA monomer. Stain Technol 1982;57:121-6.

[29] Cho TJ, Gerstenfeld LC, Einhorn TA. Differential temporal expression of members of the transforming growth factor beta superfamily during murine fracture healing. J Bone Miner Res 2002;17:513-20.

[30] Karasek MA. Does transformation of microvascular endothelial cells into myofibroblasts play a key role in the etiology and pathology of fibrotic disease? Med Hypotheses 2007;68:650.

[31] Sarrazy V, Billet F, Micallef L, Coulomb B, Desmoulière A. Mechanisms of pathological scarring: role of myofibroblasts and current developments. Wound Repair Regen September/October 2011;19(Suppl. s1):s10-5.

[32] Lienau J, Schmidt-Bleek K, Peters A, Haschke F, Duda GN, Perka C, et al. Differential regulation of blood vessel formation between standard and delayed bone healing. J Orthop Res 2009;27:1133-40.

[33] Medici D, Shore EM, Lounev VY, Kaplan FS, Kalluri R, Olsen BR. Conversion of vascular endothelial cells into multipotent stem-like cells. Nat Med 2011;16:1400.

[34] Grcevic D, Pejda S, Matthews BG, Repic D, Wang L, Li H, et al. In vivo fate mapping identifies mesenchymal progenitor cells. Stem Cells 2012;30:187-96.

[35] Sakamoto A, Yoshida T, Yamamoto H, Oda Y, Tsuneyoshi M, Iwamoto Y. Congenital pseudarthrosis of the tibia: analysis of the histology and the NF1 gene. J Orthop Sci 2007; 12:361-5.

[36] Grande MT, Lopez-Novoa JM. Fibroblast activation and myofibroblast generation in obstructive nephropathy. Nat Rev Nephrol 2009;5:319-28.

[37] Lawton DM, Andrew JG, Marsh DR, Hoyland JA, Freemont AJ. Mature osteoblasts in human non-union fractures express collagen type III. Mol Pathol 1997;50: 194-7.

[38] Mahnken AH, Staatz G, Hermanns B, Gunther RW, Weber M. Congenital pseudarthrosis of the tibia in pediatric patients. Am J Roentgenol 2001;177:1025-9.

[39] Mariaud-Schmidt RP, Rosales-Quintana S, Bitar E, Fajardo D, Chiapa-Robles G, Gonzalez-Mendoza A, et al. Hamartoma involving the pseudarthrosis site in patients with neurofibromatosis type 1. Pediatr Dev Pathol 2005;8:190-6. 